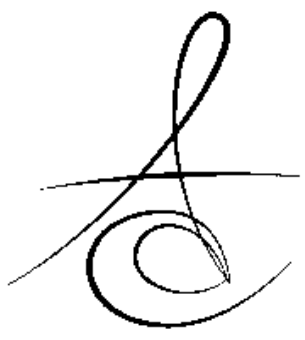

Makale Kodu/Article code: 2726

Makale Gönderilme tarihi: $\quad 28.03 .2016$

Kabul Tarihi: 13.04.2016

\section{Dİş ÜSTÜ PROTEZLERDE SCHUBİGER ATAȘMAN DİZAYNININ MODİFİYE KULLANIMI: OLGU SUNUMU}

\author{
THE MODIFIED USAGE OF SCHUBIGER ATTACHMENT DESIGN IN \\ OVERDENTURES: A CASE REPORT
}

Doç.Dr. Rifat GÖZNELí

Prof.Dr. Yasemin KULAK-ÖZKAN*

\section{ÖZET}

Diş üstü protez, protezin mukozal yüzeyinin bir veya daha fazla destek dişin üzerini sararak destek aldığı protezlerdir. Protezin tutuculuk ve stabilitesini arttırmak amacıyla, kalan destek dişler üzerine inşa edilebilen farklı ataşman çeşitleri kullanılmaktadır. Schubiger ataşman dizaynı da destek dişleri bar tutuculara bağlayan prefabrike vidalardan oluşur. Bu rapor prefabrike formu yerine modifiye Schubiger ataşman dizaynının kullanıldığı diş üstü protezlerle tedavi edilmiş kısmı dişsiz bir vakayı anlatmaktadır.

Otuzbir yaşındaki erkek hasta çok sayıda diş eksikliği şikâyeti ile Protetik Diş Tedavisi departmanımıza başvurmuştur. Hastanın periodontal hastalığa bağlı olarak birçok dişini kaybettiği anlaşılmıştır. Hastanın ağız içi muayenesinde geri kalan dişlerinin (\#13, \#21, \#23, \#26, \#27, \#33, \#37, \#43, \#45) stabilizasyonda avantajlı bir şekilde çapraz ark konumunda bulunduğu ancak konvansiyonel hareketli bölümlü protez için klinik kron boylarının çok yüksek olduğu görülmüştür. Tüm olası tedavi seçenekleri hasta ile görüşülüp, hem ideal estetik ve fonksiyonun sağlandığı hem de ileride uygulanması düşünülebilecek implant destekli sabit protetik tedavi amacıyla kemik kaybını engelleyecek bir diş üstü protez yapılması yönünde seçim yapılmıştır. $\mathrm{Bu}$ sayede, hastanın geri kalan kemik dokusunun korunabileceği ve prefabrike ataşmanlara göre maliyeti uygun bir tedavi sağlanmıştır. Uygulanan tedavi ile hastanın estetik ve fonksiyon ihtiyacı karşılanmıştır.

Anahtar Kelimeler: Diş üstü protez, Kısmi dişsizlik, Schubiger bağlantı
ABSTRACT

An overdenture is a prosthesis that supplies support from one or more abutment teeth by covering them beneath its mucosal surface. Different kinds of attachment systems, which are constructed on existed abutment teeth are used to increase the retention and stability of the denture. Schubiger attachment design is one of the attachments, which consists of prefabricated screws to connect the abutment teeth to bar retainers. This report presents the rehabilitation of a partially edentulous case with teeth supported overdentures in which modified Schubiger attachment design was used instead of its prefabricated form.

A 31-year-old male patient reported with the chief complaint of many missing teeth in our Department of Prosthodontics. The patient's history revealed missing teeth due to periodontal disease. Intraoral examination revealed that remaining teeth were located in cross arch as an advantage in stabilization (\#13, \#21, \#23, \#26, \#27, \#33, \#37, \#43, \#45), but the height of the clinical crowns were so high to rehabilitate by a conventional removable partial denture. All situations were discussed with the patient and an overdenture treatment plan was choosen for both having the ideal esthetic, function and preventing the loss of alveolar bone for possible implant supported fixed prosthesis rehabilitation in the future. Thus, both preventive treatment on existing bone and cost effective treatment to the use of prefabricated attachments were obtained. The applied treatment met the patient's needs such as esthetic and function.

Keywords: Overdenture, Partially edentulous, Schubiger attachment.

\footnotetext{
*Marmara Üniversitesi, Diş Hekimliği Fakültesi, Protetik Diş Tedavisi AD
} 


\section{GİRİş}

Dişler fonksiyon ve estetiğin yanı sıra, kişinin dental sağlığının da prognozunu etkilemesi açısından önemlidir. Diş kaybı ile birlikte dişsiz alanlardaki kemik rezorbsiyonunu hızlanarak artar, kalan dişler üzerine iletilen kuvvetlerin yönü ve miktarı değişerek; ağızda kalan dişlerin de sağlığı etkilenir. ${ }^{1}$ Kalan dişlerin, yıkıcı oklüzal kuvvetlerin yönü ve miktarı karşısında idamesini sağlayacak uygun bir protetik tedavi uygulanmaması sonucunda zamanla tam çene dişsizliğe neden olunabilir. ${ }^{1,2}$ Hâlbuki rezorbsiyon problemi başlamadan önce alveolar kemiği korumak düşünülmesi gereken bir konudur. Bu nedenle bir veya daha fazla kalmış uygun desteklikte dişler kullanılarak diş üstü protez uygulanması oldukça önemlidir. Bu sayede ileride implant yapılması düşünülen vakalarda, kalan dişleri çevreleyen kemik dokuda rezorbsiyonun engellenmesi sağlanır. ${ }^{3}$

Diş üstü tam protezler, bir veya daha fazla doğal dişten destek alınarak parsiyel dişsiz vakaların protetik rehabilitasyonunu sağlayan hareketli protezlerdir. $^{3}$ Bu rehabilitasyonda destek dişler ve tam protez, başlık veya ataşman tutuculu olabilen farklı yapılarla birbirine bağlanabilir. Bu sayede; 1- Protezin destek, tutuculuk ve stabilitesi artar, 2- Tutuculuk ve stabilitenin artmasıyla hastanın proteze adaptasyonu kolaylaşır, 3- Alveol kemiğine iletilen horizontal kuvvetler ve tork kuvvetleri azalır, 4- Proprioseptif cevabın devamlılı̆ı sağlanır, 5- Dişlerin varlığı hastayı psikolojik olarak rahatlatır, 6- Aşırı rezorbe kretli vakalarda tatminkâr bir estetik elde edilir, 7- Destek dişlerin kaybedilmesi durumunda kolayca total proteze çevrilebilir. ${ }^{4}$ Konvansiyonel tam proteze göre oldukça avantajlı bir uygulama olmasının yanında uygun vakalarda hazırlanması da önemlidir. Başlıca endikasyonlarını sıralayacak olursak: 1. Tek tam protezler, 2. Damak yarıkları ve cerrahi defekt vakaları, 3. Hipodonti vakaları, 4. Dikey boyutun da düştüğü aşırı aşınma vakaları, 5. Alt tam protez uygulandığında hasta adaptasyonunun problem olabileceği vakalar, 6. Hareketli bölümlü proteze destek olarak kullanılması riskli destek dişlerin bulunduğu vakalardır. ${ }^{3}$

Diş üstü protezlerin destek diş ile bağlantısı başlık veya çeşitli tutucu ataşmanlar ile sağlanır. ${ }^{5,6}$ Kök üzerinden destek alan basit başlıklar hastalar tarafından maliyet açısından her ne kadar prefabrik tutucu ataşmanlara göre daha fazla tercih edilse de, uzun dönemde hasta konforu ve memnuniyeti açısından prefabrike ataşmanlar avantaj sağlamaktadır. ${ }^{7}$ Buna rağmen, prefabrike ataşman maliyetini karşılayamayacak hastalarda maliyet performansı daha uygun olabilecek şekilde modifiye edilerek dökümden elde edilmesi mümkün olabilir. ${ }^{8}$

Schubiger ataşman destek dişe vida sistemi ile bağlanan, tam protezin tutuculuk ve desteğini bu destek dişler arasında konumlandırılmış bar tutucular ile sağlayan bir dizayndır. Destek dişlerin paralel olmadığı durumlarda kullanılır. Uzun dönemde tek ataşman destekliye dönüştürülebilecek şekildeki ayrık köklerde ve bar sabitlemeye uygun destek dişlerde ideal bir yapıdır. Sistemin dezavantajı ise kök yüzeyi üzerinde fazlaca bir hacim oluşturmasıdır. ${ }^{9}$

$\mathrm{Bu}$ olgu raporunda; alt ve üst çene parsiyel diş eksikliği olan hastanın, Schubiger ataşman dizaynının aslına uygun şekilde modifiye edilip dökümden oluşturularak kullanıldığı diş üstü protez ile protetik rehabilitasyonu anlatılmıştır.

\section{KLİNİK RAPOR}

Çok sayıda diş eksikliği olan 31 yaşındaki erkek hasta Diş Hekimliği Fakültesi Protetik Diş Tedavisi Anabilim Dalımıza başvurmuştur. Hastanın periodontal hastalığa bağlı olarak dişlerini kaybettiği anlaşılmıştır. Ağızda kalan dişlerin periodontal sağlığı, kron-kök oranları klinik ve radyografik olarak incelenmiş ve destek olarak kalacak dişler belirlenmiştir. Hastanın estetik ve fonksiyonunu geri kazanma isteğini karşılamak için çeşitli tedavi alternatifleri sunulmuştur. Hastanın klinik kron boylarının çok uzun olması, hem horizontal kuvvetlerin destek dişler üzerindeki yıkıcı etkisinin fazla olabileceğinden, hem de yeterli estetiğin sağlanamayacağından dolayı hareketli bölümlü protez tedavi alternatiflerinin dışında bırakılmıştır. Hastanın yaşının oldukça genç olması implant destekli sabit protetik rehabilitasyon düşünülmesi gerekliliğini ortaya koysa da, hastanın sosyoekonomik durumunun uygun olmaması sebebi ile başka tedavi seçenekleri değerlendirilmek üzere sunulmuştur. Ağızda kalan dişlerinin de çekilip tam protez uygulaması isteyen hastaya, mevcut dişlerinin ağızda bırakılarak yapılacak bir diş üstü protezle hem protezin desteğinin daha fazla olacağı hem de dişler etrafındaki kemik dokusu rezorbsiyonunun yavaşlatılacağı, böylece ekonomik durumunun uygun olduğu dönemde implant üstü pro- 
tetik tedavi şansının devam edebileceği anlatılmıştır.

Birbirlerinden farklı konumlarda; simetriğe yakın pozisyonlarda olan destek dişlerin (diş \# 13, 21, $23,26,27,33,37,43,45$ ) bulunması ve arklar arası yeterli mesafe olması dolayısıyla bar tutuculu bir diş üstü protez ile tedavinin uygunluğuna karar verildi (Resim 1). Diş üstü protezin tutuculuğu için destek dişler arasında bar tutucu parçaların olduğu, bar tutucuların destek dişlere Schubiger ataşman dizaynında kullanılan prefabrik vida sisteminden farklı olarak modifiye edilmiş, simante döküm postların kullanıldığı bir sistem planland.

$\mathrm{Bu}$ sistemin uygulanabilirliğinin tam kontrolü amacıyla; alt ve üst çeneye hazırlanan kaide-mum duvarlar ile hastanın var olan dikey boyutunun ve interoklüzal mesafenin tam protez altında kullanılacak tutucu elemanlar için yeterli olduğu görüldü. Tedavi planı hastaya anlatııı, onayı alındı. Diş üstü protez altında destek olarak kullanılacak 13, 21, 23, 33, 43 ve 45 nolu dişlere endodontik tedavileri uygulandı ve 21 , 23, 33 ve 43 nolu dişler dişeti üzerinde $3 \mathrm{~mm}$ kalacak şekilde boyları kısaltıldı (Resim 2). Bir sonraki seansta destek dişlerin post yuvaları hazırlandı ve silikon esası ölçü materyali (Speedex; Coltène/Whaledent AG, Altstätten, İsviçre) ile post ölçüleri alındı. Ölçüden elde edilen alçı model üzerinde Schubiger ataşman dizaynının tutucu elamanlarının modifiye edilmiş şekli modelaj işlemi ile oluşturulduktan sonra, $\mathrm{Cr}$-Co alaşımdan (Heraenium P; Heraeus Kulzer, Hanau, Almanya) döküm yoluyla elde edildi. Bu sayede üst çenede 21 ve 23 nolu, alt çenede 33 ve 43 nolu dişlerin kök kanalından döküm postlarla destek alan ve üst çenede 13 nolu, alt çenede 37 ve 45 nolu dişlerde hazırlanan metal kopinglere bağlanan bar tutuculu bir sistem hazırlandı. Üst çenede 3 destek diş arasında 2 bar eleman, alt çenede 4 destek diş arasında 3 bar eleman tesis edildi (Resim 3,4). Hastanın hareketli protezinin oluşturulacağı modeli elde etmek için, döküm alaşım tutucu elemanların da ağızda olduğu konumda, silikon esaslı ölçü materyali (Speedex; Coltène/Whaledent AG, Altstätten, İsviçre) kullanarak 1 aşamalı ölçü tekniği ile ölçüleri alındı. Tutucu dişi parçaların da yerleştirildiği metal iskelet alt yapılar kullanılarak vertikal ve horizontal ilişkiler tespit edilip tekrar artikulatöre alındı. Dişli prova aşamasında hastanın da görsel onayı alındıktan sonra, protezin bitim işlemleri gerçekleştirildi. Protezin hasta ağzında kontrolü sonrasında, modifiye Schubiger dizaynının tutucu parçaları cam iyonomer siman (Ketac-Cem; 3M ESPE, St. Paul, ABD) ile simante edildi. Hastaya protezin takılıp çıkartılması ve hijyeninin sağlanması konusundaki bilgilendirmeler yapıldıktan sonra protezler teslim edildi (Resim 5). Hastanın ilk 1,5 yıldaki 3. periyodik takibinde protezlerini estetik ve fonksiyonel olarak tatminkâr bir şekilde kullanabildiği, destek dişlerin destekliğini koruduğu ve desimantasyon oluşmadığı görüldü.

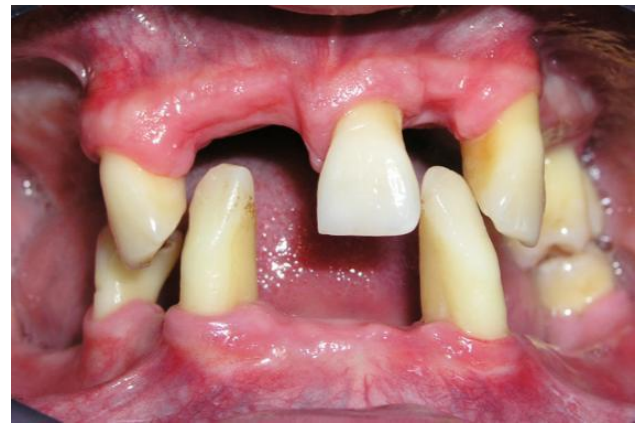

Resim 1. Destek dişlerin ağız içi görüntüsü.

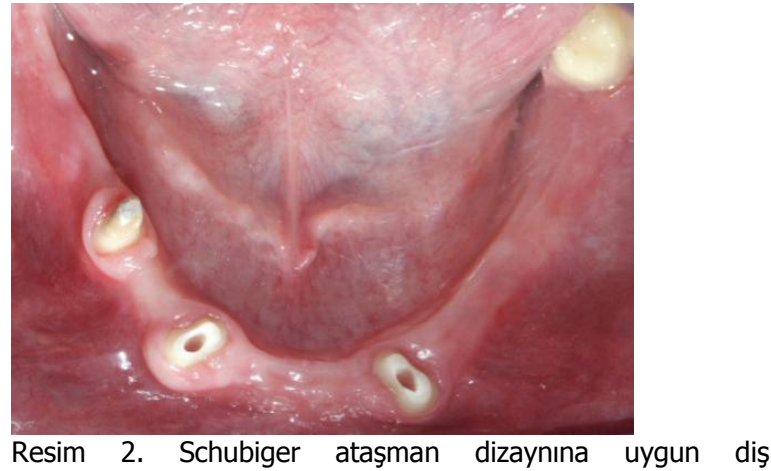
preparasyonu.

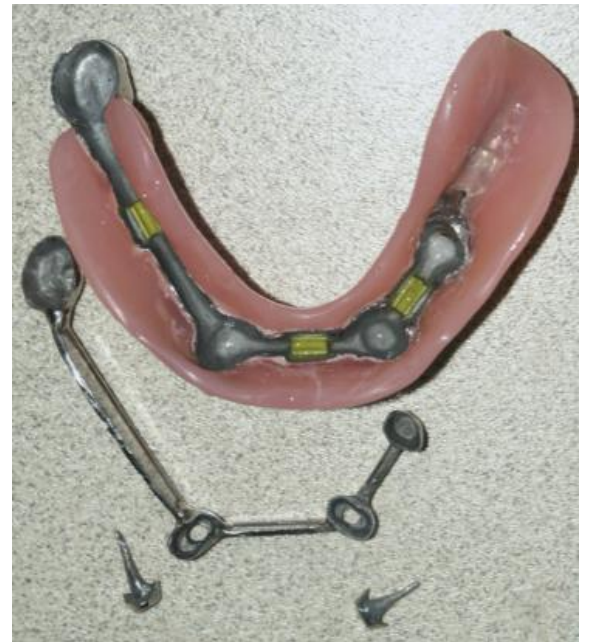

Resim 3. Schubiger ataşman sisteminin parçaları. 


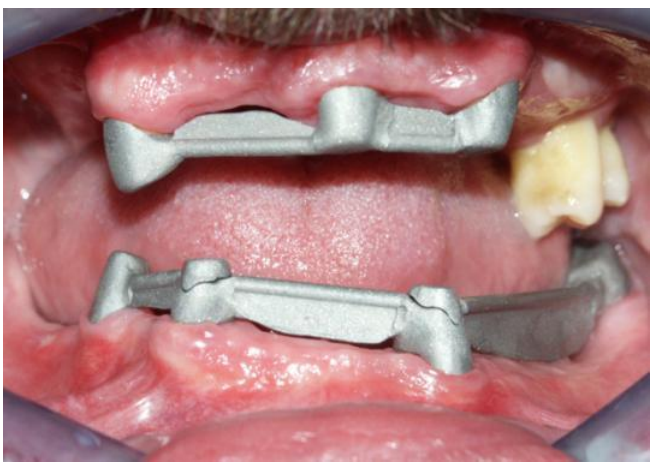

Resim 4. Schubiger ataşman sisteminin ağız içi görüntüsü.

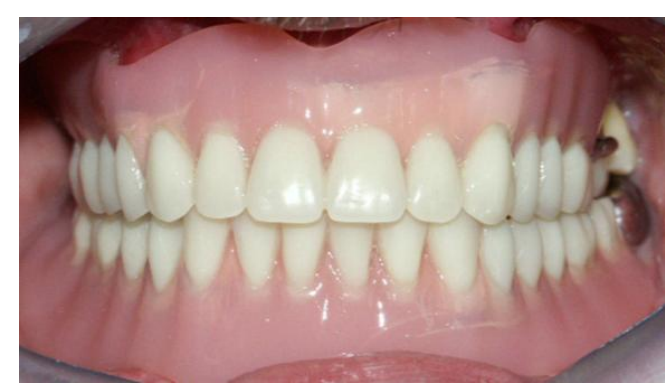

Resim 5. Diş üstü protezin ağız içi görüntüsü.

\section{TARTIŞMA}

Günümüzde implant destekli sabit protetik restorasyonlar her ne kadar kısmi ve tam dişsiz ağızlarda en uygun ve popüler tedavi alternatifi olarak görünse de; çoğu hastanın ekonomik durumu maliyeti yüksek olan bu tedavi şeklini karşılamaya yetemeyebilmektedir. Kimi ekonomik durumu yeterli olan hastanın ise; ileri cerrahi yöntemler olmaksızın implant destekli sabit protetik restorasyon uygulamayı mümkün kılacak derecede kemik doku desteği bulunmayabilmektedir. ${ }^{7}$ Bu yüzden, implant üstü sabit protetik restorasyonlarla tedavi edilebilecek genç bir hastayı, o an için ekonomik durumunun elvermemesi sebebi ile klinik kron boyları uzamış destek dişlerini üzerine gelecek yatay kuvvetlerle kısa zamanda kaybedebileceği hareketli bölümlü protez ile veya estetik kaygılardan ötürü kalan dişlerin çekimini takiben tam protez uygulamaları yerine, diş üstü protez ile tedavi edilmesi daha uygun olacaktır. Böylece, destek dişler etrafındaki kemik doku korunarak hastanın ekonomik durumunun yeterli olduğu durumda implant destekli sabit restorasyon uygulaması herhangi bir ileri cerrahi tekniği ile kemik ogmentasyonu gerekmeyecektir.,3

Az sayıda destek dişi kalmış, kısmi dişsiz bir hastada, doğal dişlerinin çekilip yerine tam protez uygulanması, çoğu zaman tercih edilen bir tedavi yöntemi değildir. Sağlıklı ve uygun konumda birkaç doğal dişin veya kökün ağızda bırakılması proprioseptif etkinin korunması, destek dişler etrafındaki kemik doku kaybının engellenmesi, tutuculuk ve stabiliteye katkıda bulunarak hastaya psikolojik destek sağlaması açısından önemlidir. ${ }^{4,10}$ Bir çift simetrik dişin diş üstü protezde destek olarak kullanılmasının tutuculuğu belirgin derecede arttırdığı bildirilmiştir. ${ }^{11}$ Çiğneme etkinliği açısından da diş üstü protezlerin konvansiyonel tam protezlere göre daha etkili olduğu rapor edilmiştir. ${ }^{12}$ Bu yüzden, bu vakada tutuculuk ve çiğneme etkinliğinin hasta memnuniyeti açısından önemi göz önüne alınarak, tam proteze göre avantajlı bir tedavi şekli olan; uygun dizaynda planlanmış bir diş üstü protez uygulandı.

İmplant destekli veya diş destekli tam protezlerin uygulanmasında kullanılan farklı tipte tutucu ataşmanlar mevcuttur. Ataşman seçiminde arklar arası mesafe, destek dişlerin durumu ve konumu, kolay uygulanabilme ve maliyet gibi faktörler etkili olur. ${ }^{3}$ Schubiger ataşman destek dişe fabrikasyon hazırlanmış yivli post vidalar ile bağlanır ve tutuculuk bu vidaların arasında konumlandırılmış bar tutucular ile sağlanır. ${ }^{9}$ Sistemin avantajlarının yanında maliyet dezavantajı çoğu ataşman sisteminde olduğu gibi yüksektir. Bu yüzden bu çalışmada, Schubiger ataşman dizaynının destek ve tutuculuk avantajlarından faydalanılırken, maliyet dezavantajı dizaynın dökümden oluşturulması ile elimine edilmiştir.

\section{SONUÇ}

Diş üstü protezler ile; az sayıda dişi kalmış kısmi dişsiz bir vakanın protetik tedavisinde, uygun dizayn seçilerek tutuculuk ve stabilizasyonun tatmin edici düzeyde sağlanabilmesi, ayrıca ileride implant uygulanabilecek vakanın kemik rezorbsiyonunun yavaşlatılması ve implant için gerekli olan sert dokunun korunması mümkün olabilmektedir. Bununla birlikte, düşük maliyet sağlanması amacıyla Schubiger ataşman dizaynının da modifiye edilerek dökümden hazırlanması ile aslına benzer derecede tatminkâr sonuçlar sağlanabilmektedir.

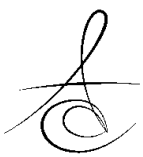




\section{KAYNAKLAR}

1. Zarb GA, Bolender CL, Carlsson GE. Boucher's prosthodontic treatment for edentulous patients. 11th ed. St. Louis; Mosby Co.:2003.

2. Saintrain MV, de Souza EH. Impact of tooth loss on the quality of life. Gerodontology 2012;29:e632-6.

3. Basker RM, Harrison A, Ralph JP. Overdentures in general dental practice. 2nd ed. London; British Dental Association: 1988.

4. Prakash VS, Shivaprakash G, Hegde S, Nagarajappa. Four and two tooth supportedConventional over denture: two case reports. Int J Oral Health Sci 2013;3:61-4.

5. Schuch C, de Moraes AP, Sarkis-Onofre R, PereiraCenci T, Boscato N. An alternative method fort he fabrication of a root-supported overdenture: A clinical report. J Prosthet Dent 2013;109:1-4.

6. Gonda $T$, Ikebe K, Ono T, Nokubi T. Effect of magnetic attachment with stres breaker on lateral stres to abutment tooth under overdenture. J Oral Rehabil 2004;31:1001-6.

7. Carlsson GE. Implant and root supported overdentures - a literature review and some data on bone loss in edentulous jaws. J Adv Prosthodont 2014;6:245-52.

8. Bansal SB, Aras MA, Chitre V. Tooth supported overdenture retained with custom attachments. ] Indian Prosthodont Soc 2014;14:283-6.

9. Jenkins G. Precision attachments: A link to successfull restorative treatment. 1st ed. Leipzig; Quintessence Publishing Co.: 1999.

10. Pehlivan N, Özkan P, Karacaer Ö. Klinik kron boyu kısa dişlerin protetik rehabilitasyonu: Olgu sunumu. Atatürk Üniv Diş Hek Fak Derg 2012;5:29-33.

11. Crum RJ, RooneyGE. Alveolar bone loss in overdentures: a 5 year longitudinal study. J Prosthet Dent 1978;40:610-3.

12. Rissin L, House JE, Manly RS, Kapur KK. Clinical comparison of masticatory performance and electromyographic activity of patients with complete dentures, overdentures and natural teeth. J Prosthet Dent 1978;39:508-11.

\section{Yazışma Adresi}

Doç. Dr. Rifat Gözneli

Marmara Üniversitesi

Sağlık Bilimleri Kampusü,

Dişhekimliği Fakültesi,

Başıbüyük, Maltepe-İstanbul

e-mail: rgozneli@superonline.com

Telefon: 0216421 0613-1776

Faks: 02164210291 